https://www.journal-imab-bg.org

Original article

\title{
VITAMIN D STATUS AND DIETARY HABITS OF CHILDREN WITH ADOLESCENT IDIOPATHIC SCOLIOSIS IN VARNA
}

\author{
Dimitar B. Marinov, Teodora T. Dimitrova \\ Department of Hygiene and Epidemiology, Faculty of Public Health, Medical \\ University of Varna, Bulgaria.
}

\begin{abstract}
Background: Adolescent idiopathic scoliosis (AIS) is a very common condition amongst adolescents in Bulgaria, as well as in Europe. Few factors play a role in the etiopathogenesis, one of which is the lifestyle, specifically the levels of some nutrients, and anthropometrics. They can be described as aspects of the nutritional status of patients with AIS.

Purpose: This ongoing study aims to access the vit. $\mathrm{D}_{3}$ and dietary habits of children with AIS in Varna.

Methods: Data was collected from 77 participants so far, using anthropometric measurements, food questionnaires and biochemical testing for vit. $\mathrm{D}_{3}$ levels in blood serum of all children without contraindications or objections (34 out of the 77).

Results: Out of 34, 3\% are sufficient, while $47 \%$ are insufficient and $50 \%$ are with moderate to severe levels of deficiency. The level of consumption of fish amongst all the participants so far is below the recommendations. The level of consumption of eggs, despite the low amount of vit. $\mathrm{D}_{3}$ in the egg yolk also has a correlation to the levels of vit. $\mathrm{D}_{3}$. Participants supplementing with vit $\mathrm{D}_{3}$ or multivitamins containing it had similar average levels to the children not supplementing.

Conclusions: The data so far shows that participants might be in need of more information about fish consumption recommendations and how to properly supplement with vit $\mathrm{D}_{3}$.
\end{abstract}

Keywords: adolescent idiopathic scoliosis, vitaminD deficiency, food frequency, supplementation,

\section{INTRODUCTION}

Adolescent idiopathic scoliosis (AIS) is one of the most common non-infectious conditions amongst adolescents in Bulgaria, alongside obesity, myopia, and asthma, and affects $4-5 \%$ of all adolescents [1]. The condition is more prevalent in females, especially the more severe cases. Etiology is multifactorial and exact causes remain unknown. Six groups of factors are proposed to have a role genetics, hormonal, abnormalities in the nervous system, abnormal skeletal growth, biomechanical and lifestyle factors [2]. Lifestyle factors include nutrition, diet, calcium and vitamin $\mathrm{D}_{3}$ intake, and physical activity. The effect of those lifestyle factors can be evaluated using aspects of the nutritional status of these children.

Previous studies have shown that there might be some correlation between the vit. $\mathrm{D}_{3}$ status and the condition AIS [3]. Vitamin D is proven to have a role in calcium homeostasis, immunomodulation, antiproliferative effects and more [4]. According to the Endocrine Society, the maximum benefits of vitamin $\mathrm{D}$ are achieved only at blood levels above $30 \mathrm{ng} / \mathrm{ml}$ (above $70 \mathrm{nmol} / \mathrm{l}$ ) [5].

Vitamin D deficiency affects almost $50 \%$ of the whole world's population [6]. This makes it the most common vitamin deficit. Scientists are even considering it as a pandemic [7]. It does affect people of every age, gender, race, and country [8]. The causes for this are many but mostly related to a short and ineffective exposition to direct sunlight. Not spending enough time out in the sun is a common lifestyle for the modern society and contributes to the high incidence of vitamin D deficiency.

This data is part of an ongoing study of the nutritional status and physical activity of children with adolescents and includes the aspects of dietary habits and vit. $\mathrm{D}_{3}$ status.

\section{OBJECTIVES}

The objectives of this ongoing study include the assessment of the vit. $\mathrm{D}_{3}$ status and the dietary habits of children with AIS in Varna.

\section{MATERIALS AND METHODS}

The study so far has included 77 participants with AIS from Varna, aged 10-18. The study includes three sets of measurements collected with the permission of the parents. The first set consists of full anthropometric data collected for every participating child, including bioimpedancemetry body composition analysis, using standardized techniques [9]. The second set assesses the dietary habits and the physical activity of the participants, through questionnaires including food frequency questionnaire (FFQ) and 72-hr food dairy, as well as standardized questionnaires for physical activity of adolescents (PAQ-A). The third set includes biochemical testing for vit. $\mathrm{D}_{3}$ levels in blood serum of all children without contraindications and further consent of the parents after thorough risk evaluation. For this paper we are going to use the data collected 
by the FFQ and the biochemical tests, to evaluate the vit. D3 status and the dietary habits of the children with AIS.

\section{RESULTS}

In this ongoing study, 34 of the 77 participants so far, haven't declined or shown any contraindications for testing their blood serum levels of vit. $\mathrm{D}_{3}$. Using the referent ranges defined by The Endocrine Society [5], of all children tested, only 1 is sufficient, 16 are insufficient and 17 are deficient. 4 out of the 17 deficient have a very severe deficiency (levels below $10 \mathrm{ng} / \mathrm{ml}$ ) [Figure 1]. In percentages, only $3 \%$ are sufficient, while $47 \%$ are insufficient and $50 \%$ are with moderate to severe levels of deficiency [Figure 2].

Fig. 1. Levels of vit. $\mathrm{D}_{3}$ in the tested subjects. Using the referent ranges defined by The Endocrine Society, of all children tested, only 1 is sufficient, 16 are insufficient and 17 are deficient. 4 out of the 17 deficient have a very severe deficiency (levels below $10 \mathrm{ng} / \mathrm{ml}$ ).

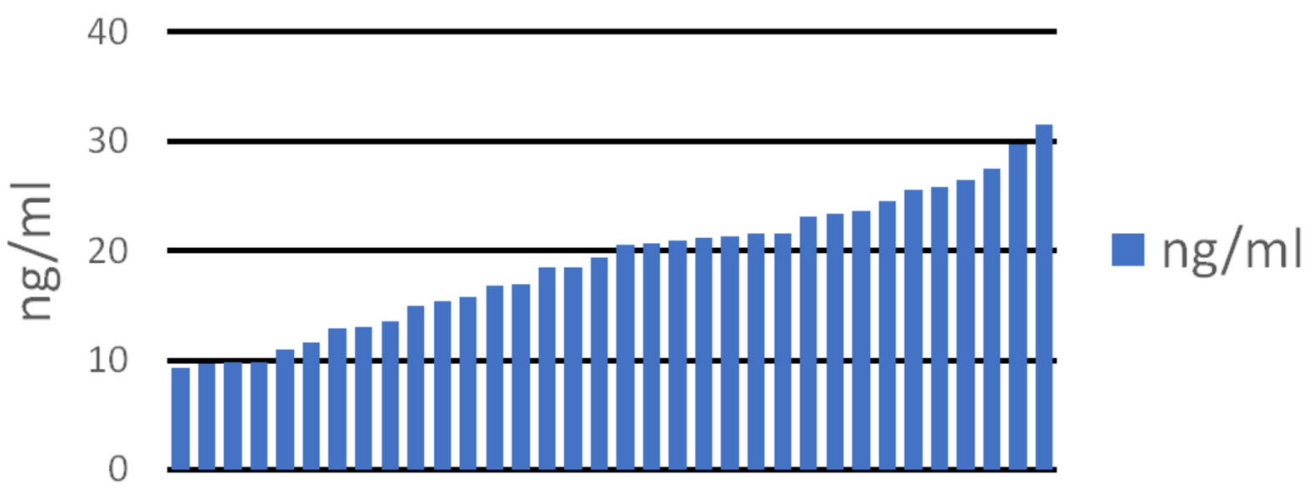

Fig. 2. The results so far show that only $3 \%$ are sufficient, while $47 \%$ are insufficient and $50 \%$ are with moderate to severe levels of deficiency.

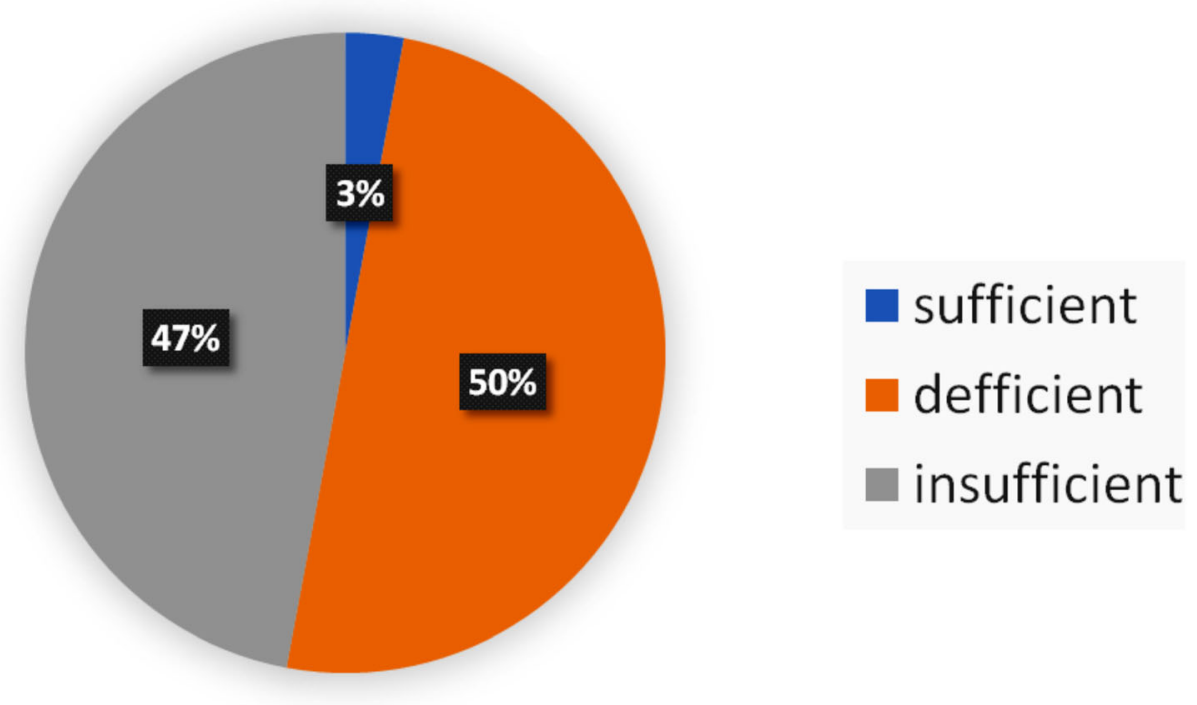

The level of consumption of fish amongst all the participants so far is below the recommendations by the Bulgarian National Center for Public Health and Analysis for children (at least twice per week) [10]. The level of consumption of eggs amongst the participants was mostly meeting the recommendations and despite the low amount of vit. $\mathrm{D}_{3}$ in the egg yolk has shown a correlation to the levels of vit. $\mathrm{D}_{3}$. The correlation is weak but statistically significant - Spearman correlation is $0.354, \mathrm{p}<0.05$ [Figure 3]. 
Fig. 3. Correlation between egg yolk consumption and levels of vit. $D_{3}$. The level of consumption of eggs, despite the low amount of vit. $\mathrm{D}_{3}$ in the egg yolk has a statistically significant correlation to the level of vit. $\mathrm{D}_{3}$. of participants - Spearman correlation is $0.354, \mathrm{p}<0.05$.

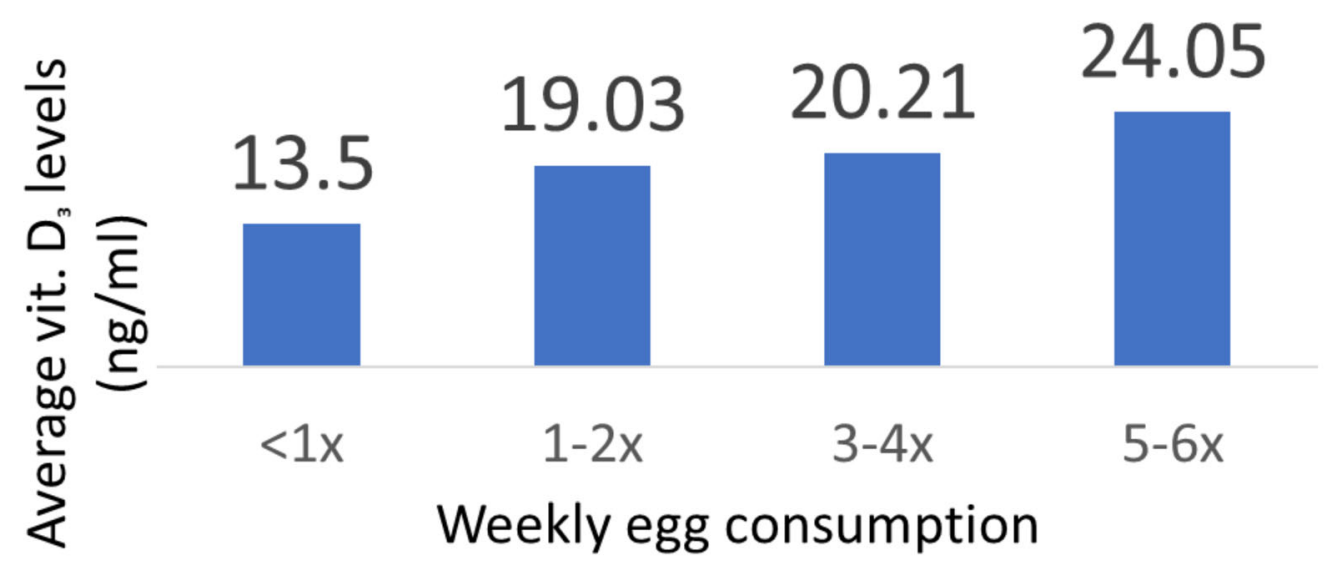

In regards to supplementation, participants supplementing with vit $\mathrm{D}_{3}$ or multivitamins containing it had average levels of $21.6 \mathrm{ng} / \mathrm{ml}$, in comparison to $17.5 \mathrm{ng} / \mathrm{ml}$ in children not supplementing.

\section{DISCUSSION}

Very few foods are natural sources of vit. $\mathrm{D}_{2}$ or vit. $\mathrm{D}_{3}$. They include fish, egg yolk and certain mushrooms [5]. There are also fortified foods, usually modified milk and milk products, which however are not present in Bulgaria. Supplementation is also an effective source of vit. $\mathrm{D}_{3}$.

Studies show that from the sources mentioned, fish is the best natural food source of vit. $\mathrm{D}_{3}$. and higher consumption responds to significantly higher vit. $\mathrm{D}_{3}$ levels. [11] Our observations also show that fish consumption amongst children is below the recommendations. Some studies suggest that even these recommendations might not be quite sufficient in terms of vit. $\mathrm{D}_{3}$ supply [11].

Similar data has been published by other authors. A representative study among Varna girls shows that $68 \%$ are at risk of vitamin $\mathrm{D}$ deficiency during the colder seasons due to low fish consumption [12]

Another study in Varna of 352 subjects found the lowest fish consumption is among young people (up to 20 years old) and the highest among people over 60 [13].

The small difference in the vit. $\mathrm{D}_{3}$ levels amongst supplementing and non-supplementing participants might show that subjects either don't supplement with high enough doses or they are not well informed how the supplements have to be taken, in order to be effective [14].

Because vitamin D is a fat-soluble vitamin, it is crucial that the patients are properly instructed on how to take the supplement. The recommendations are to intake it with fatty foods, preferably during the largest meal. This ensures an optimal release of bile and pancreatic enzymes required for optimal absorption. Many medications and supplements can reduce its bioavailability. Vitamin D supplements should not be taken together with statins, anticonvulsants, corticosteroids, and fiber-rich meals or supplements.

\section{CONCLUSION}

There is strong evidence about tendencies in the nutritional status of children with AIS, mainly regarding the levels of vit. D3. These tendencies can be affected by lifestyle factors like supplementation and dietary intake. However, the recommendations for the consumption of fish to the general public might need revision. Also, this study might be showing that subjects are not well informed about how to supplement properly.

This research will continue to evaluate the exact relations and effects of different lifestyle factors and other aspects of the nutritional status of children with AIS.

\section{REFERENCES:}

1. Marinov DB, Hristova DN, Dimitrova TT. Aspects of the nutritional status of children with adolescent idiopathic scoliosis. Literature review. J of IMAB. 2018 Oct-Dec; 24(4):2281-2284. [Crossref]

2. Wang WJ, Yeung HY, Chu WCW, Tang NL-S, Lee KM, Qiu Y, et al. Top theories for the etiopathogenesis of adolescent idiopathic scoliosis. $J$
Pediatr Orthop. 2011 Jan-Feb;31(1 Suppl):S14-27. [PubMed] [Crossref]

3. Batista R, Martins DE, Hayashi

LF, Lazaretti-Castro M, Puertas EB, Wajchenberg M. Association between vitamin D serum levels and adolescent idiopathic scoliosis. Scoliosis. 2014 Dec 4;9(Suppl 1):O45. [PMC] [Crossref] 4. Holick MF. Vitamin D: A Clin Endocrinol Metab. 2011

millenium perspective. $J$ Cell Biochem. 2003 Feb 1;88(2):296-307. [PubMed] [Crossref]

5. Holick MF, Binkley NC, Bischoff-Ferrari HA, Gordon CM, Hanley DA, Heaney RP, et al. Evaluation, treatment, and prevention of vitamin D deficiency: an Endocrine Society clinical practice guideline. $J$ 
Ju1;96(7):1911-30.

[Crossref]

[PubMed]

6. Nair R, Maseeh A. Vitamin D: The "sunshine" vitamin. J Pharmacol Pharmacother. 2012 Apr;3(2):118-26. [PubMed] [Crossref]

7. Cashman KD, Dowling KG, Škrabáková Z, Gonzalez-Gross M, Valtueña J, De Henauw S, et al. Vitamin D deficiency in Europe: pandemic? Am J Clin Nutr. 2016 Apr;103(4):1033-44. [PubMed] [Crossref]

8. Holick MF, Chen TC. Vitamin D deficiency: a worldwide problem with health consequences. Am J Clin Nutr. 2008 Apr;87(4):1080S-6S. [PubMed]

\section{[Crossref]}

9. World Health Organization. Training Course on Child Growth Assessment. WHO Child Growth Standards. WHO. 2008. [Internet]

10. [Recommendations for healthy nutrition of students aged 7-19 in Bulgaria.] [in Bulgarian] Ministry of health, NCPHA, Sofia. 2008. [Internet]

11. Lehmann U, Gjessing HR, Hirche F, Mueller-Belecke A, Gudbrandsen OA, Ueland PM, et al. Efficacy of fish intake on vitamin D status: a meta-analysis of randomized controlled trials. Am J Clin Nutr. 2015 Oct; 102(4):837-47. [PubMed] [Crossref]

12. Naydenova D. [Body composi- tion and nutritional status assessment in adolescents] [monograph] ISBN 978-619-7137-29-3. Varna (Bulgaria): www.zape4at.com; 2015. 87-89 p. [in Bulgarian].

13. Naydenova D, Porojanova S, Kavaldzhieva B, Dimitrova E, Gerov $\mathrm{T}$. [Fish products in the nutrition of the Black Sea population] The science of dietetics. 2011, Sofia (Bulgaria): www. arbilis.com; 19-22 p. [in Bulgarian]

14. Mulligan GB, Licata A. Taking vitamin $\mathrm{D}$ with the largest meal improves absorption and results in higher serum levels of 25-hydroxyvitamin D. J Bone Miner Res. 2010 Apr;25(4): 928-30. [PubMed] [Crossref]

Please cite this article as: Marinov DB, Dimitrova TT. Vitamin D status and dietary habits of children with adolescent idiopathic scoliosis in Varna. J of IMAB. 2021 Jan-Mar;27(1):3589-3592.

DOI: https://doi.org/10.5272/jimab.2021271.3589

Received: 08/11/2019; Published online: 17/01/2021

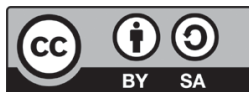

\section{Address for correspondence}

Dimitar Borisov Marinov

Department of Hygiene and Epidemiology, Medical University - Varna,

55, Marin Drinov Str., Varna, Bulgaria

E-mail: mitak_1992@abv.bg 